Covered in: CrossRef; RePEC; CEEOL; Google Scholar.

\section{Training Dragons... The Dragon Archetype as the Contradictions, Paradoxes and Dialectics of Organizations. A Study in NLP}

\section{Gabriel Remus SUCIU1}

${ }^{1}$ Independent Researcher, Brasov, Romania, gabriel_remus_suciu@yahoo.com
Abstract: This article presents the archetype of the dragon as well as the realities it refers to - the contradictions, paradoxes and dialects lurking in any organization. And the NLP (Neuro Linguistic Programming) studies could fit in this complex model. More specifically, their elements - namely: i) the paradoxes, ii) the binds, and iii) the nested levels could exemplify the dynamics of the dragon archetype.

Near the end of the article, the author proposed other solutions based on assumptions (instead of the nested levels): these proposed solutions are rather advices and guesses than hard and scientific facts. For who can guarantees that science is the final answer to life and eternity?

Keywords: Archetype; dragon archetype; NLP (Neuro Linguistic Programming); paradoxes; binds; nested levels; assumptions.

How to cite: Suciu, G.R. (2019). Training Dragons... The Dragon Archetype as the Contradictions, Paradoxes and Dialectics of Organizations. A Study in NLP. Journal of Mediation \& Social Welfare, 1(1), 01-21. doi:10.18662/jmsw/01 
The archetypes are like the buds of a honeycomb filled with the honey of the experience that every human being seeks in the valleys, meadows and forests of life; therefore, the archetypes, in the Jungian perspective, are potentials that are activated based on experience. Carl Gustav Jung presenting the archetypes said they are: pattern of behaviors (Jung, 1960: 335), or imprint (Jung, 1968: 41). Jung also used associations with philosophical and scientific terms: for instance, he exemplified the archetypes with such philosophical concepts like God image (Philo Judeus), or Ideas (Platon) (Jung, 1969: 2); he also referred to such scientific notions like: collective representations (Levy Bruhl), elementary ideas (Bastian), or categories of imagination (Hubert and Mauss) (Jung, 1969: 3, 2001: 12). While these are other labels for the archetypes, their name is borrowed from i) Irenaeus and ii) Dionysius the Aeropagite, and their definition is similar with that offered by iii) St. Augustine (Jung, 1969: 2).

Monika Kostera applied the Jungian archetypes to the realities of the organizations. In the same manner that Jung considered that human personality can be viewed from the perspective of archetypes, so Kostera considered that organizational culture could be studied from the perspective of archetypes. In her book "Organizations and archetypes" (2012), she presented 12 archetypes that are unified by the Self. Some of these are archetypes of personality, and others are archetypes of transformation. First of all, the archetypes of personality could be divided into two classes: the class of "archetypes as such" - for instance: shadow/ persona, anima/ animus; and the class of "archetypal images" - for example: sage/ Gaia, king/ adventurer, and trickster/ eternal child. Secondly, concerning the archetypes of transformation, Kostera presented the couple of birth/ death/ rebirth in the form of the two opposites: cosmogony/ soteriology. Starting from her book, it can be stated that in the human's life certain archetypes (for example, trickster/ eternal child) have the chance to develop earlier than others (like sage/ Gaia), the development having a trajectory from simple to complex. 


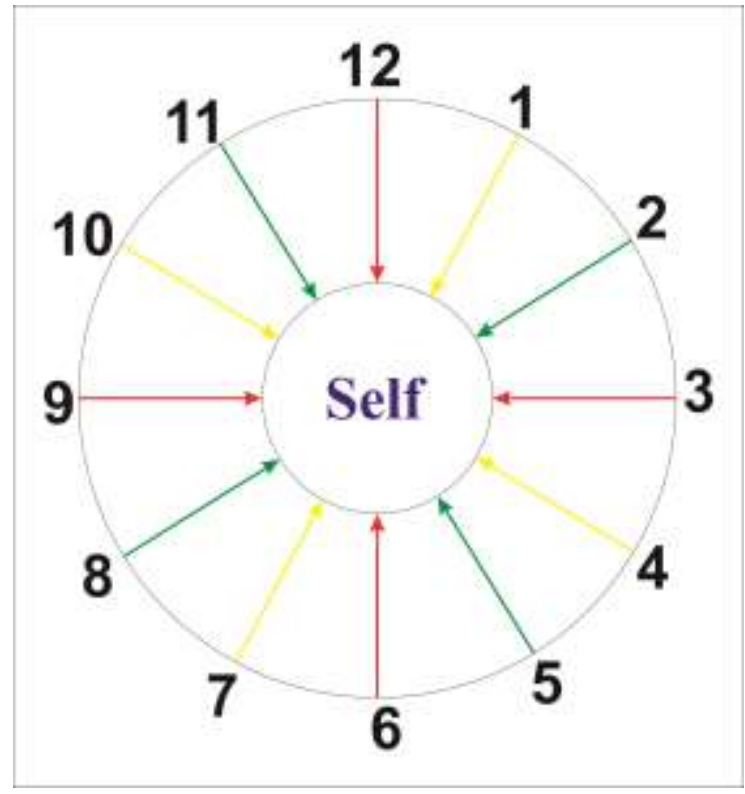

In this article it will be presented the archetype of the dragon as well as the realities it refers to - the contradictions, paradoxes and dialects lurking in any organization.

\section{The dragon archetype}

The dragon archetype has two contradictory faces: the dragon as enemy - according to the Western vision, and the dragon as ally - according to the Eastern vision. So, according to the Western vision, which can be exemplified with stories like "Beowulf" or "The Hobbit", the hero has the task to slay the beast: life and civilization depend on the destruction of the dragon by the hero. But according to the Eastern view, the dragon is not demonized, but - on the contrary - divinized: only with the help of a dragon the hero can prove the difficulty in his journey to fulfillment and wisdom. And this vision is most often found in stories such as those of "Mulan" or "Saiyuki" (Moore, 2003: 13).

The dragon as enemy is a mountain dragon. It has four legs, two bat-like wings, a long neck and tail, and a thick coat of protective scales, although there is always one vulnerable patch, usually somewhere on the creature's belly. Many account and illustrations give it horns. (Greer, 2011: 136) Additional attributes include the ability to breathe fire, poisonous breath, numerous heads, and the ability to cast magical spells, such as shape- 
shifting. (Bane, 2016: 106) The dragon lives high up in a mountain or deep within a cave. Young maidens are sacrificed to appease the dragon's hunger and desire. Beside maidens, the hunger and desire of a dragon is also oriented toward a treasure, for the dragon hoards it. So, the hero must slay the dragon, save the maiden, and retrieve the treasure. (Bane, 2016: 106)

On the contrary, the dragon as ally is a water and sky dragon. It has the horns of a stag, the head of a camel, the eyes of a demon, the neck of a snake, the belly of a clam, the scales of a carp, the claws of an eagle, the feet of a tiger, and the ears of a cow. (Greer, 2011: 136) Most have a pearl, either in the mouth or just under the chin, which allows them to breathe fire, or emit some sort of mist. (Bane, 2016: 107) The dragon lives in palaces high in the sky, or deep under the ocean. It loves jewelry, but jade most of all. (Bane, 2016: 107) The dragon brings rain and symbolizes the power of the King and the prosperity of the country. All creatures (including the hero/ the heroine) are the progeny of the dragon. (Bane, 2016: 107)

Regardless of its two contradictory faces, the dragon symbolizes the contradictions, paradoxes and dialectics hidden in organizations.

\section{Organizational studies}

The most recent and encompassing article written in organizational studies is entitled "Contradictions, dialectics and paradoxes in organizations: A constitutive approach", being coauthored by Linda Putnam, Gail Fairhurst and Scott Banghart in 2016. The three authors present a model with i) 3 causes, ii) 6 effects and iii) 3 solutions. So...

- Primo, the 3 causes are: the contradictions, paradoxes and dialectics. These are, in fact, the dragons - either as enemy, or as ally hidden in the organizations. The difference between these three dragons is in their simplicity, or in their complexity. The contradictions are formed only of opposites, while the paradoxes are organized by the opposites and dualities; finally, the dialectics contain both of them being composed of opposites, dualities and transcendences. (Clegg \& Pina E Cunha, 2017: 112; Putnam, Fairhurst, \& Banghart, 2016: 6-8)

- Secundo, the 6 effects are as follows: i) vicious and virtuous cycles, ii) double binds and paralysis, iii) unintended and unanticipated consequences, iv) enabling and contrasting actions, v) opening up and closing off participation, and vi) transforming and reproducing organizations (Putnam et al., 2016: 19).

- Tertio, the authors presented also 3 solutions: i) either... or... solutions, ii) both... and... solutions, and iii) neither... nor... solutions. The 
either... or... approaches treat contradictory poles as distinct phenomena that function independent of each other and fit into three broad areas: 1) defensive mechanisms, 2) selection and 3) separation. (Putnam et al., 2016: 58) The both... and... approaches differ from "either... or..." responses through treating opposites as inseparable and interdependent. The literature reveals three types of "both... and..." approaches: 1) paradoxical thinking, 2) vacillation and 3) integration/ balance. (Putnam et al., 2016: 59-60) Finally, the neither... nor... approaches focus on connecting oppositional pairs, moving outside of them, or situating them in a new relationship. This category consists of three clusters: 1) reframing/ transcendence, 2) connecting, third spaces, dialogue, and 3) reflective practice and serious play. (Putnam et al., 2016: 64)

\begin{tabular}{|c|c|c|}
\hline Causes & Effects & Solutions \\
\hline Contradictions & $\begin{array}{l}\text { Vicious \& virtuous cycles } \\
\text { Double binds \& paralysis }\end{array}$ & Either... or... \\
\hline Paradoxes & $\begin{array}{l}\text { Unintended \& unanticipated } \\
\text { consequences }\end{array}$ & Both... and... \\
\hline Dialectics & $\begin{array}{l}\text { Enabling \& contrasting actions } \\
\text { Opening up \& closing off } \\
\text { participation } \\
\text { Transforming \& reproducing } \\
\text { organizations }\end{array}$ & Neither...nor... \\
\hline
\end{tabular}

In the following pages of this article it will be discussed how the NLP (Neuro Linguistic Programming) studies could fit in this complex model. More specifically, three elements - namely: i) the paradoxes, ii) the binds, and iii) the reframing (see neither... nor... solutions) - of the Putnam, Fairhurst, and Banghart (2016) article will be the subject of the study in NLP.

\section{A study in NLP (Neuro Linguistic Programming)}

Although the NLP field is very large, it will probably be remembered, as the years will pass by, in the annals of the history of psychology, by the study of paradoxes, binds, and their solutions, namely the nested levels (where the "framing" and "reframing" techniques belong). So, in the following pages it will be presented three NLP important concepts: i) the paradoxes, ii) the binds, and iii) the nested levels. 
Training Dragons... The Dragon Archetype as the Contradictions, Paradoxes ... Gabriel Remus SUCIU

\section{1) The paradoxes}

Four examples of paradoxes will be analyzed; keeping in mind the fact that the NLP forerunners and representatives studied many more paradoxes and a new article would be needed just to classify them. The four examples are: i) the nine dots puzzle, ii) the liar paradox, iii) the omnipotence paradox and iv) the Catch-22.

- The nine dots puzzle. This puzzle is also known as Christopher Columbus' egg puzzle (Gardner, 1960: 93, 1967: 105; Loyd, 1914: 301). The nine dots are arranged in an imaginary square with a dot - the ninth - in the middle of it. By definition a square has four sides. And a side is a line. However, the puzzler is asking to draw four lines for four sides and a dot. So, if the nine dots are arranged in a square with a central point, and if the square has four lines as its sides, all the nine points cannot be connected by four lines. In return, if all the nine points can be connected by four lines, and by definition a square has four lines as its sides, then the nine dots aren't arranged in a square with a central point.

"Nine dots [are arranged in a square]. Four lines must be drawn in such a manner that all dots will be passed trough. The pencil must not be taken from the paper and no line should be retraced." (Maier, 1930: 141-142) "Nine dots are arranged in a square. The problem is to connect them by drawing four continuous straight lines without lifting pencil from paper." (Scheerer, 1963: 119)

- The liar paradox. This paradox is attributed to Epimenides, the Cretan. If the Cretan is lying, then all Cretan are telling the truth, which means the Cretan is not lying. However, if Epimenides is telling the truth, then all Cretans are liars, which mean the Cretan is lying.

"One of themselves, a prophet of their own [Epimenides, the Cretan] said $<$ Cretans are always liars, evil beasts, idle gluttons $>$ " (Bible, Titus 1:12)

- The omnipotence paradox. This paradox states the following implications: if God is omnipotent, and if He can create a stone He cannot lift, then He is not omnipotent; however, if God is not omnipotent, and if He can't create a stone He cannot lift, then God is omnipotent.

"Can God create a stone too heavy for Him to lift?" (Mavrodes, 1963: 221; Savage, 1969: 74).

- The Catch-22. Joseph Heller has written a famous book where he presented many definitions of "Catch-22". However, one of these formulations states that: if every pilot who refuses to fly in the war is sane, and if only sane pilots can fly in the war, then they will fly in the war. More than that, if every pilot who accepts to fly in the war is crazy, and if only crazy pilots can't fly in the war, then they will not fly in the war. 
"There was only one catch and that was Catch-22, which specified that a concern for one's own safety in the face of dangers that were real and immediate was the process of a rational mind. Orr was crazy and could be grounded. All he had to do was ask; and as soon as he did, he would no longer be crasy and would have to fly more missions. Orr would be crasy to fly more missions and sane if he didn't, but if he was sane he had to fly them. If he flew them he was crary and didn't have to; but if he didn't want to he was sane and had to." (Heller, 1996: 46)

These four paradoxes appear in the work of NLP forerunners and representatives which will be briefly listed: Paul Watzlawick $(1974,1976)$, Watzlawick, Helmick Beavin, and Jackson (1967), Robert Dilts (1998), Dilts and DeLozier (2000) and Joe Cheal (2008 a, 2008 b)

\section{2) The binds}

The distinction between single, double, triple and infinite binds lies in imagining a ladder with multiple steps, or levels. When only one level is occupied by the problem then it can be said there is a "single bind". When the problem is to be found at two levels, then the problem is a "double bind". Following this rule, it can be imagined also a "triple bind", and even an "infinite bind", if and only if the ladder can be imagined with infinite bars, whereas the problem is expanding all along these levels. When someone is saying "Damned if I do, and damned if I don't" he/ she is caught in a single bind. However if he/ she is adding "damned if I don't decide" to the first statements, then the single bind is in fact a double bind. And going one step further, the triple bind could be expressed like this: "Damned if I do, damned if I don't, damned if I don't decide, and damned for being unable to decide". However, for a person to be lost in the infinite bind, he/ she must be such a brilliant mind in logic and, unfortunately, unaware of its strengths. And it's more than a fact that the formula of the infinite bind can't be presented here, or else the article will never end... So, for this article it's enough to present some examples of single and double binds!

- The single bind. In Chaucer's Canterbury tales there is a story of the wife of a knight. This knight is faced with a series of choices and, after he made one choice, he has to choose again and again, being doomed to the eternal act of choice. The series of choices are broken, however, when the knight chooses not to choose any longer. And this is a classical case when the problem is sheltered at only one level.

" $<$ Choose now $>$ said she, <one of these two things, / To have me foul and old until I die/ And be to you a faithful bumble wife,/ And never displease you in all my life/ Or else to have me young and beautiful,/ And take your chances on the visitors/ 
Training Dragons... The Dragon Archetype as the Contradictions, Paradoxes ... Gabriel Remus SUCIU

Who will come to your house because of me, / Or meet me somewhere else, as well may be,/ Now choose yourself which you prefer>/ This knight pondered and sighed wretchedly/ But at last he spoke in this manner/ $<M y$ lady and my love, and wife so dear, / I place myself under your management/ Choose yourself whichever may bring most pleasure/ And most honor to you as well as me/ I make no choice of either of the two;/ For whichever pleases you suffices me $>$ / $<$ Then I have won mastery over you $>$ said she, I $<$ Since I may choose, and run things as I please? > / <Yes, certainly, wife >, said he, $<I$ think it best $>$ / $<$ Kiss me $>$, said she, <we are no longer enemies; / For, on my honor, I will be both to you,/That is to say, yes, both beautiful and good (...)>" (Chaucer \& Hopper, 1970: 461-462)

For more analyses on this subject, the reader is invited to browse the following NLP documents: Watzlawick, Weakland, and Fisch (1974: 38-39), Lawley (2000), and Lawley, and Tompkins (2003: 183-184)

- The double bind. This type of bind is present at two levels: the concrete level and the abstract level. This is the case when it's denied the denial, it's forbidden talking about the fact that it is forbidden to talk, it's unseen the fact that it can't be seen. This is, also, the case of the doublethinking.

"Winston sank his arms to his side and slowly refilled his lungs with air. His mind slid away into the labyrinthine world of doubletbink. To know and not to know, to be conscious of complete truthfulness while telling carefully constructed lies, to hold simultaneously two opinions which cancelled out, knowing them to be contradictory and believing in both of them, to use logic against logic, to repudiate morality while laying claim to it, to believe that democracy was impossible and that the Party was the guardian of democracy, to forget whatever it was necessary to forget, then to draw it back into memory again at the moment when it was needed, and then promptly to forget it again: and above all, to apply the same process to the process itself. That was the ultimate subtlety: consciously to induce unconsciousness, and then, once again, to become unconscious of the act of hypnosis you had jus performed. Eve to understand the word <doubletbink> involved the use of doubletbink." (Orwell, 1949: 19)

It's useless to mention that several other NLP thinkers talked about this phenomenon, thinkers like: Bateson (1977: 279-308) or Lawley (2013).

\section{3) The nested levels}

Here, the NLP field is understood broadly, comprising NLP representatives (like Bandler, Grinder and Dilts), NLP forerunners (as Korzybski, Hayakawa, Bateson, Watzlawick and Satir) and the forerunners of NLP forerunners (for instance Russell). All these intellectuals staged, at one point or another of their lives, a vision of nested levels, of levels above 
levels, of levels above levels above levels, and so on and on; but not endlessly, having a start and an end...

\section{- Russell - the logical types}

In the work of Bertrand Russell three ideas are important: i) the distinction between the class and its members, a distinction which, taken to the extreme, leads to ii) the paradoxes. And the third ideas is how these paradoxes are solved with the introduction of iii) the hierarchy of logical types. So, the class/ member distinction have to be arranged according to logical types. The first type contains only members. The second type contains classes who contain members of the first type. The third type contains classes of classes whose members are classes of the second type. And so on with classes of classes of classes. Etc, etc. For instance, there are two paradoxical propositions: "I'm saying lies", and "I'm saying the truth". The first proposition is well-known in the philosophical literature, while the second one, although it is the reverse of the first one, was never mentioned till now. This is the reason I'll use only the first sentence to exemplify the theory of the logical types. Parenthetically, this proposition is also known as "the liar paradox". This paradox can be solved, according to Russell, as follows: i) at the first level I have the sentence "I'm saying lies". If anyone asks me whether this is true or false, then I, ii) at a second level, can mention: "It is true that <I'm saying lies>". Thus, according to Russell, the paradox is solved by placing the propositions at various logical levels. In the example above, the sentence "I'm saying lies" is a member of the sentence "It is true" which is its own class. (Russell, 2010a: 534-535, 2010b: 104)

\section{- Korzybski - the structural differential}

Alfred Korzybski presented the structural differential in his book "Science and Sanity. An Introduction to Non-Aristotelian Systems". In that book he has a dispute with Aristotle and, implicitly, with some of his present time's (1933) thinkers - such as Dewey or Watson. While these thinkers stated the definition that "humans are animals", Korzybski said that we can only say that: "humans are humans". In fact, Korzybski observed that between humans (represented by Smith) and animals (represented by Fido) there is a difference of abstraction. While for animals the abstraction is limited, the abstraction is limitless for humans. And this unlimited abstraction for Smith, for humans, involves four ingredients: i) the event (or the world as it is in time, space and like particles), ii) the object (or what we see, hear, taste, touch, and smell - in other word, what we sense, perceive and represent), iii) the description (or the labels, the words attached to the object) and iv) the inference (or the ideas, opinions, meanings that can go 
infinitely on the abstraction ladder). For instance, let's take Emily driving as an example. i) The street, traffic, trees, rain, wipers represent the event. This event is acknowledged by Emily ii) at the object level: her eyes capture reflected light from images in her field of view. So she sees the following facts iii) described by her as such: "I was driving 50 feet from the car ahead. A dark vehicle, driven by a middle-aged man, emerged from my left field of view. He was going faster than me. He suddenly accelerated and veered into the lane directly in front of me, reducing my following distance to less than 10 feet, which meant that: a) this guy is a jerk because b) he cut me off and almost made me have a wreck... c) This being a reason I don't want to go to work, but - instead - I want to go home and relax with my dog. d) Etc, etc, etc". Where a), b), c) and d) are different levels of inference, a) being very concrete, and d) being very abstract. (Korzybski, 2000: 386-411)

\section{- Hayakawa - the abstraction ladder}

The abstraction ladder is a visually illustration presented by Samuel Ichiye Hayakawa after the Korzybski distinction between i) the map and the territory, and ii) this map and other maps. Being a ladder, "the abstraction ladder" is an axis, a dimension, a continuum, having at the upper end the "maps", and at the lower end the "territory". This ladder has four steps: i) the idea, ii) the word, iii) the object and iv) the process. The "idea" is the most abstract step, being situated at the upper end of the ladder; while the "process" is the most concrete step, being situated at the lower end of the ladder. To fully understand these distinctions, let's talk about Bessie, the cow. She is a living organism, constantly changing, constantly ingesting food and air, transforming it, and getting rid of it again. iv) Bessie is a process: at the most concrete end, Bessie is a process; view microscopically she is a mass of variegated corpuscles, cells and bacterial organism; in a sentence, she is a perpetual dance of electrons. Then, iii) Bessie is an object. climbing "the ladder of abstraction", Bessie is an animal, resembling other animals of like size, functions, and habits; she is a cow. Following that, ii) Bessie is a word: taking another step on this ladder, Bessie could be viewed as many words as: the word "Bessie" or the word "cow"; so, little by little, Bessie became an abstraction. And finally, i) Bessie is an idea: Bessie is "a bovine", she is also "a quadruped", and "an animal", not to mention that she is "an organism"; as you could guess, Hayakawa is talking now not about territory, but about different kinds of maps. (Hayakawa, 1952: 165-185)

\section{- Bateson - the logical levels of learning}

In the article "The logical categories of learning and communication" from the book "Steps to an ecology of mind", Bateson stated his theory of 
"levels of learning". Other labels for the level of "learning II" are: deuteronlearning, set learning, learning to learn, and transfer of learning. These being said, Bateson defined the levels of learning in the following manner: "i) Zero learning is characterized by specificity of response, which - right or wrong - is not subject to correction. ii) Learning $I$ is change in specificity of response by correction of errors of choice within a set of alternatives. iii) Learning II is change in the process of Learning I, e.g., a corrective change in the set of alternatives from which choice is made, or it is a change in how the sequence of experience is punctuated. iv) Learning III is change in the process of Learning II, e.g. a corrective change in the system of sets of alternatives from which is made. (...) And v) Learning IV would be change in Learning III, but probably does not occur in any adult living organism on this earth." (Bateson, 1977: 293) There is therefore a difference between the mechanisms and the organisms. On the one hand, the computers can exemplify the mechanisms and their zero learning. As it is known, no computer until now has changed its operating mode by itself. On the other hand, Bateson listed mice, laymen, scientists and mystics as exemplifying the organisms. Learning I is present with mice, learning II (or learning about learning) is specific to laymen, while learning III (learning about learning about learning) pertains to scientists and mystics. Bateson believed that, theoretically, it can be speculated a learning IV, but this type of learning has never been documented so far. (Bateson, 1977: 279-308)

\section{- Watzlawick - the reality levels}

Paul Watzlawick, in his book "How real is real?", made the distinction between two types of reality: i) the objective reality that is also called "first-order reality" and that is perceived by the senses; and ii) the subjective reality that is called "second-order reality": the language is the way this reality manifests itself. The two realities are at two distinct levels, the objective reality being concrete, while the subjective reality being abstract. (Watzlawick, 1976: 140). The difference between first-order reality/ secondorder reality is mirrored by the difference between first-order of change/ second-order of change, this last distinction being present in another book written by Watzlawick and named "Change". The first-order of change occurs according to "the theory of group" stated by Evariste Galois. This theory emphasis that any totality is a combinations of its members: one such combination is between a member and an identity member (for example, 5 $+0=5$ ); another combination is between a member and an opposite member (for instance, $5+(-5)=0$ ). However, the second-order of change occurs according to "the theory of logical types" presented by Bertrand Russell and North Whitehead. According to this theory the components of a 
totality are called members, while the totality of the members is called class. The member is situated at a different level than the class. (Watzlawick, Weakland, \& Fisch, 1974: 3-6).

\section{- Satir - the Self mandala/ experience levels/ personal iceberg metaphor}

Satir developed at least two nested levels models: the first one was called "the Self mandala", while the other one had many names like: "the experience levels", or "the personal iceberg metaphor".

The Self mandala is composed by eight separate discs, coming together at the centre which is represented by the Self: i) the body (the physical part), ii) the thoughts (the intellectual part), iii) the feelings (the emotional part), iv) the senses (the representational part), v) the relationship (the interactional part), vi) the context (the environmental part), vii) the nutrition (the liquids and solids ingested), and viii) the Self (the spiritual part). Consider, for instance, that a client is unhappy because his wife left him for another man. He started drinking to sink his anger, hurt and sadness, seeing himself alone in their big house. The neighboring children started to laugh at his negligent demeanor and inappropriate conduct to the passers-by. He was well aware he needed help. (Satir, 1988: 43-50)

The experience levels (also known as "the personal iceberg metaphor") are made of seven layers: i) the self (the spiritual), ii) the yearnings (the desires), iii) the expectations (the wants), iv) the perceptions (the thoughts), v) the feelings (the emotions), vi) the coping (the stances: blamer, placater, thinker, distracter, leveler), and vii) the behavior (the actions). Let's consider the example when the father is taking fishing only one son. The second son's yearning was to be loved equally. His expectation was that his father would have taken him fishing too. His interpretation was that his father didn't love him. His feelings were disappointment, hurt, and anger towards his brother. To hide his feelings he became a blamer, acting towards the other by judging, dictating and finding faults. (Satir, Banmen, Gerber, \& Gomori, 1991: 147-174)

\section{- Bandler \& Grinder - the neuro linguistic levels}

Richard Bandler and John Grinder made the distinction between two realities, between two worlds: a) the map and b) the territory. In fact, the "map" has another three names such as "experience", "representations" and "model". Any human living explore the two worlds, the two realities using two devices: the device called i) "neuro" designed for the relationship between a map and its territory; and the device called ii) "linguistic" designed for the relationship between a map and other maps. In fact, those two 
devices - the neuro and the linguistic - are even present in the name of the psychological approach: the Neuro-Linguistic Programming (NLP)! What Bandler and Grinder were trying to say is the fact that anything starts at the concrete level, the level of "the neuro" where someone sees, hears, smells, tastes and feels something; and ends at the abstract levels of "the linguistic", as when the same person is saying: "I went near a country house, where the birds were chirping in the trees. The air was full of flowers and fresh grass smells. I stretched my hand and I picked up an apple that tasted so good". (Bandler \& Grinder, 1975: 7-8, 1977: 11)

\section{- Dilts - the neurological levels}

Robert Dilts presented the neurological levels in two different ways: in the first version he listed five levels that he visualized in the form of a totem; in the second version there is another level - the spirituality - and the six levels are organized in the form of a pyramid. So, the six levels are: i) the environment (space - where?, and time - when?), ii) the behaviors (actions what?), iii) the strategies (cognitions - how?), iv) the values (emotions why?), v) the identity (ego/ personality - who?) and vi) the spirituality (Self/ deity - for whom? for what?). For instance, let's suppose a child does well on an exam. Her performance could be explained in one of the following manners: "You passed the exam in the same room where you learned for it" (the level of environment); "You did a great job" (the level of behaviors); "Your skills are very developed" (the level of strategies); "You enjoyed so much learning on this subject" (the level of values); "You are a genius" (the level of identity); "Someone up there in the sky loves you" (the level of spirituality). (Dilts, 1990: 1-2, 1994: xxvi - xxvii, 2003: xix - xxii)

\section{More about assumptions}

The nested levels presented by the above mentioned thinkers (Russell, Korzybski, Hayakawa, Bateson, Watzlawick, Satir, Bandler \& Grinder, and Dilts) are not a real solution to paradoxes and their effect, the binds. Using the nested levels, the paradoxes/ binds are solved only at the lower levels, and only to re-generate at higher levels. And to use a right image, is to recall when the prince cut a dragon's head, and when in its place another head (or other heads?) grew up. The same happens applying the nested levels to paradoxes and binds. 
Training Dragons... The Dragon Archetype as the Contradictions, Paradoxes ... Gabriel Remus SUCIU

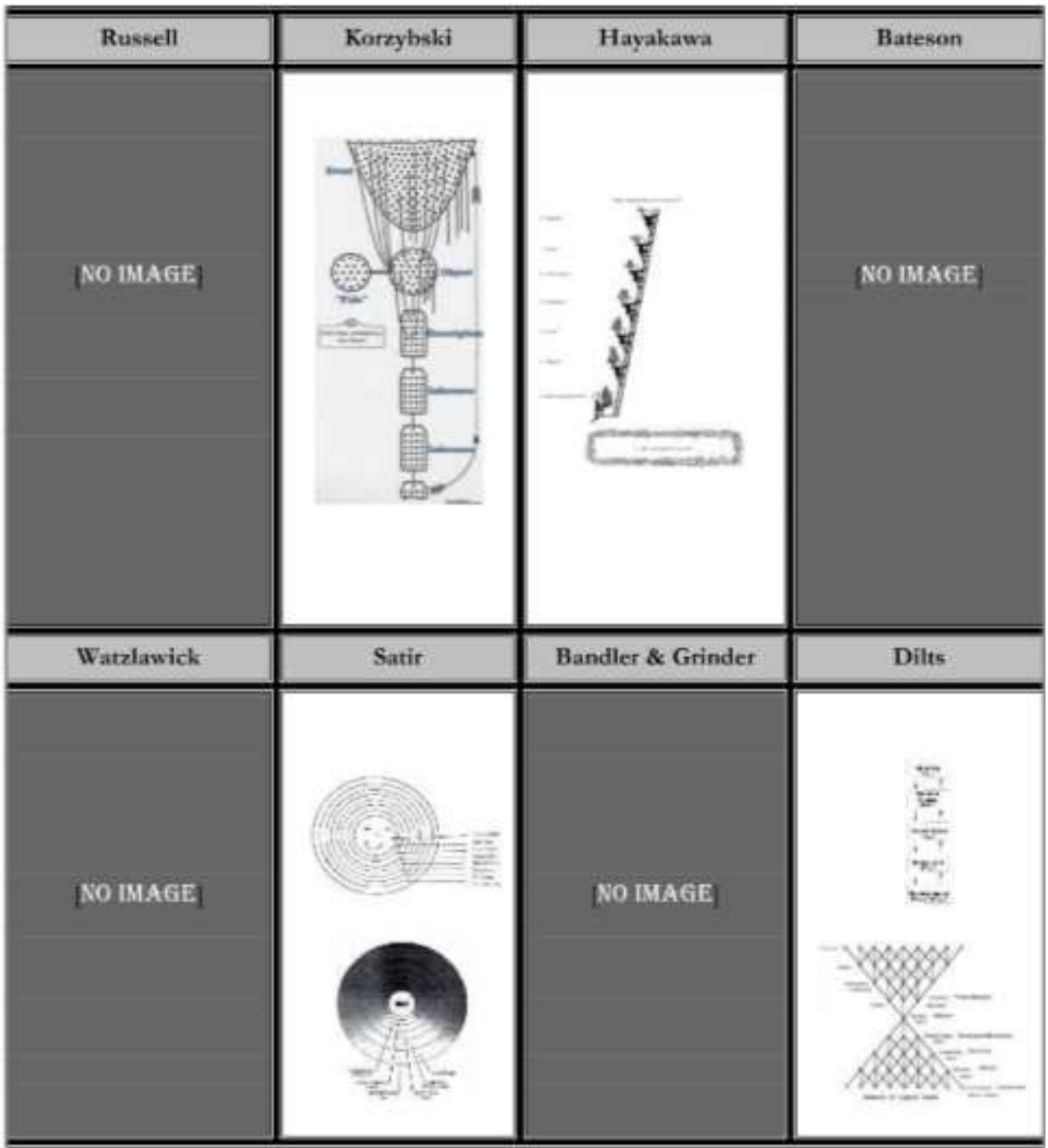

The solutions to the paradoxes and binds are based on the assumptions made. Every paradox (and bind) is based, and has its foundations, on one or more assumptions. Once these assumptions are revealed and become conscious, these assumptions lose their power, being replaced with other assumptions. So, what I'm trying to say here is science has its foundations on faith and belief, and what else are assumptions if not elements of faith and belief? 


\section{The nine dots puzzle.}

Watzlawick, Weakland and Fisch use the nine dots puzzle to illustrate how the nested levels work. They sustain the assumption that the nine dots form an imaginary square. And they say the nine dots could be connected drawing four lines outside this imaginary square. In other words, just getting out of the imaginary square, that is actually located at a concrete level, the puzzle can be solved. And getting out of the imaginary square equals having the ability to find the solution at an abstract level. (Watzlawick et al., 1974: 24-27)
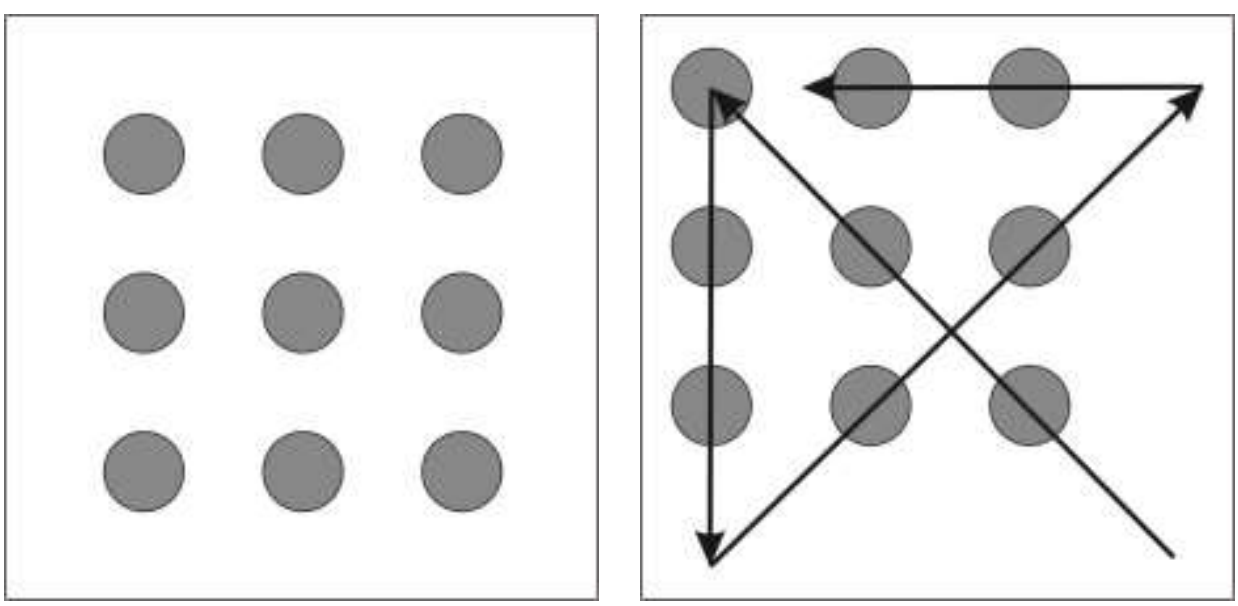

As said above, while the problem is solved at the lower levels, it reappears at higher levels. The four lines, connecting the nine dots, and drawn outside the imaginary square, can fit in another imaginary square. This second imaginary square contains nine dots that can be connected by four other lines drawn outside this second square. However, this second set of lines, already at a higher level, can fit into a third imaginary square. And so on and on. 


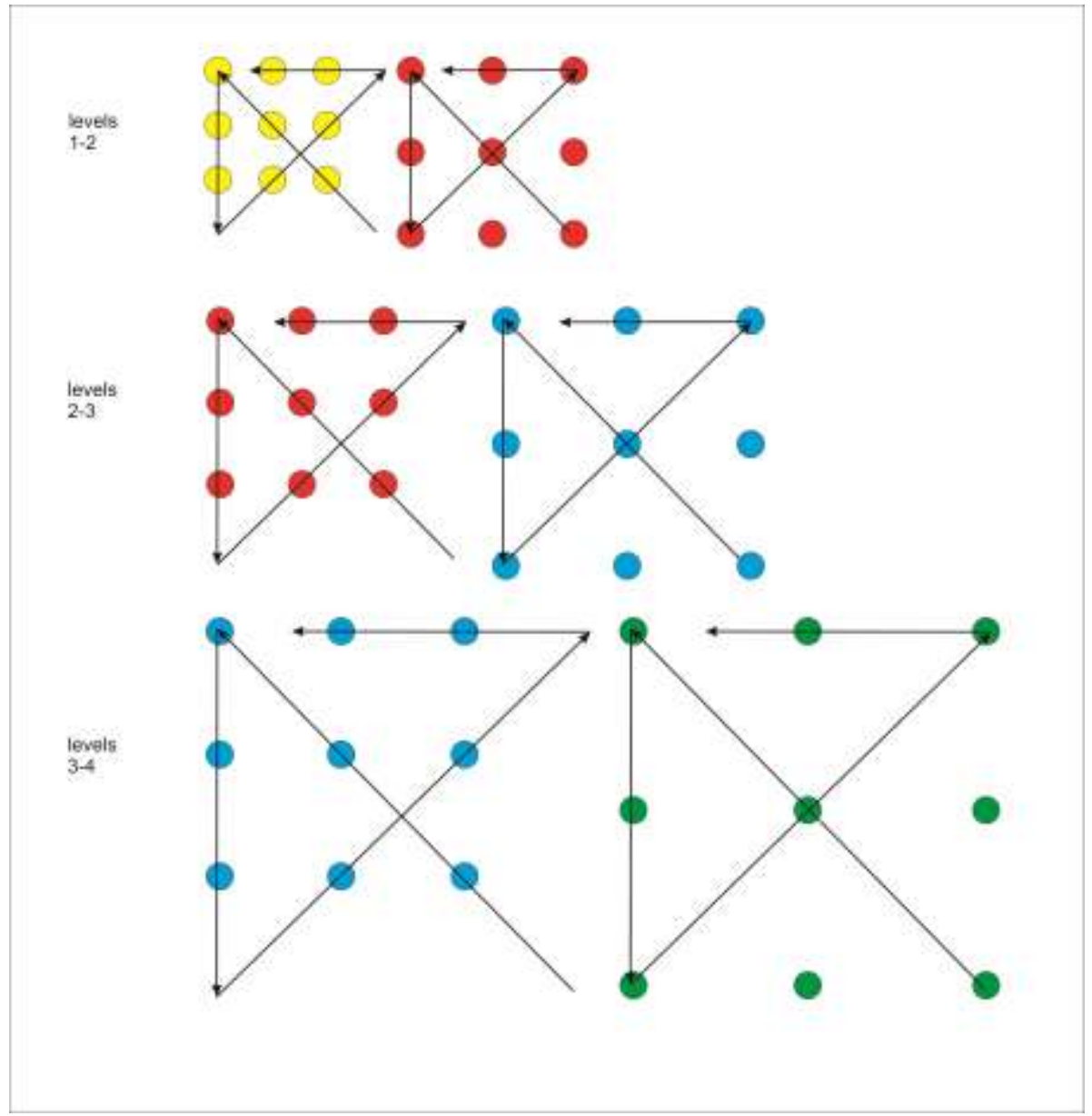

In my 2011 article "Multiple Intelligences" (Suciu, 2011) I present two assumptions as the foundation of the nine dots puzzle: 1) the dots are forming an imaginary square, and nobody can draw the lines outside its margins; and 2) the positions of the nine dots are fixed, and the nine dots are like nine nails. Considering the first assumption, I present two solutions to the puzzle - a four-line solution (the same as that presented by Watzlawick, Weakland \& Fisch) and a three-line solution. However, these solutions don't solve the puzzle once and for all: they only delay the presence of the paradox. Also, considering the second assumption, I present a solution with a line (placing the nine dots one after another, in a single file) and a solution without any line (imagining that the nine dots are nine coins which stay one above the other, in a pile). I believe that this last assumption can offer authentic solutions to the puzzle. Of course, only studying more closely the 
nine dots puzzle many more assumptions could be revealed, assumptions that will lead to genuine, or deceptive, solutions.

\section{The liar paradox and the omnipotence paradox}

These two paradoxes can be taken together because the former is concerning the human being, while the second is taking into account the nature of God. Even if Russell tried to find a solution to the liar paradox, this solution can be extended to the omnipotence paradox. Thus, Russell proceeded from the assumption that all Cretans are telling lies. And this assumption represents the first concrete level, according to which the second abstract level is defined. This abstract level shows what Epimenides said: either lies or truth. In conclusion: i) Epimenide told the truth (abstract level) that "all Cretans are telling lies" (concrete level); or ii) Epimenide lied (abstract level) that "all Cretans are telling lies" (concrete level).

The same solution can be applied to the omnipotence paradox that can be solved using the nested levels. At a first level that is concrete, it is claimed that God can create a stone too heavy for Him to lift. And at a second level, which is more abstract, one can argue whether God is omnipotent or not. These ideas can be translated as follows: i) God is omnipotent (abstract level) if "He can make a stone too heavy for Him to lift"; or ii) God is not omnipotent (abstract level) if "He can make a stone too heavy for Him to lift".

However, Russell's solution silences the paradox at the concrete levels only to give it the opportunity to express itself at the abstract levels. The question of whether all Cretans are telling lies is solved by a second question of whether Epimenides is telling lies himself or not. Therefore, instead to offer an answer to the first question, a second question is asked. At the meta-level, at the second abstract level, reappears the paradox that was solved at the first concrete level: "Epimenides tells lies" (if he says lies, then he says the truth; and if he doesn't lie, then he says lies), or its reverse: "Epimenides tells the truth" (he says the truth even when he's saying lies, just as he says lies even when he's saying the truth).

Then, the same thing happens with the omnipotence paradox. The answer to the question whether God can create a stone too heavy for Him to lift is another question: is He omnipotent? At meta-level, at the second abstract level, the paradox solved at the first concrete level reappears. And this paradox presents the things like that: if God is omnipotent, then He can do something that contradicts His omnipotence; but if He can do something contradicting His omnipotence, then $\mathrm{He}$ is no longer omnipotent. 
In fact, these paradoxes have at their foundations two assumptions: i) all Cretans (people?) say lies, and ii) God is omnipotent. As demonstrated above, these assumptions don't lead to genuine solutions. However, two other assumptions can be found at the foundations of them: i) God is as $\mathrm{He}$ wants to be, and not as some, other, or all humans want to, no matter the fact they want Him to be omnipotent; and (ii) each Cretan, and therefore every human being, is free to say whatever he/ she wants, and no one has the wrights to put words in his/ her mouth, behaving like a god or master. And my suggestion is that these second assumptions not only eliminate the need for nested levels, but also produce authentic solutions.

\section{Catch-22}

This paradox will not be analyzed here, leaving the reader the freedom to find, or not, the assumptions to solve it. However, it's worth mentioning that Watzlawick (with his reality levels) and Dilts (with the famous neurological levels) tried to solve the paradox.

\section{Conclusion}

Each one of us carries his/ her own dragons. Some are small, others are big. And they can be surpassed in their size by other dragons, even smaller, or even larger. And being a fact that each one of us has his/ her dragons, no wonder you can find them in the most restricted areas of an organization under the name of contradictions, paradoxes and dialectics.

It is not the proper place to debate whether these dragons are friends or foes. One thing, however, is sure - that they have a certain power and a certain effect on all who live in these organizations: those who look straight in their eyes are bound as under a spell. This swarming of dragons (or paradoxes) is the cause of a rigorously attested effect: the binds (which can be simple, double, triple, infinite, a little more beyond the infinite, even infinitely more beyond the infinite, and only for the beginning, without taking into account the ending...)

Next, this article presented some heroes fighting with psychological weapons like nested levels. They fought the dragons trying to break up these binds. Yet, even if their weapons were shiny and sharp, and even if they cut off more and more heads, they found out these dragons grew stronger and stronger: where a dragon's head was off, another heads were replacing it.

Ohh!, such a waste... for it's a lot easier befriending with these dragons than killing them. These creatures that haunt organizations are more valuable if they are trained. Befriending them and training them allow them 
to exist, and allow each one of us to live in harmony. And this is possible, among other things, by revealing their assumptions...

In sum, this little plea for training dragons will end here when I'll mark up the next final point.

\section{Acknowledgment}

I have created all the diagrams and tables in this article. The only exception is the diagram at the page 11 that is presented in many different sources. However, for the clarity of this paper, I think that it is sufficient to mention as inspiration Watzlawick et al. (1974: 24-27)

I'm not affiliated to any institution and no grant was offered me for writing this article. So, I assume full responsibility for all the errors as well as all the benefits of this article. For more about the article or me, please write at gabriel.suciu@ymail.com.

\section{References}

Bandler, R., \& Grinder, J. (1975). The structure of magic (1 ${ }^{\text {st }}$ vol.), A book about language and therapy. Palo Alto, USA: Science and Behavior Books.

Bandler, R., \& Grinder, J. (1977). Patterns of the bypnotic techniques of Milton H. Erickson, M.D. (1 ${ }^{\text {st }}$ vol.). Toronto, Canada: Meta Publications

Bane, T. (2016). Encyclopedia of beasts and monsters in myth, legend, and folklore. Jefferson, USA: McFarland \& Company.

Bateson, G. (1977). Steps to an ecology of mind. New York, USA: Ballantine Books.

Chaucer, G., \& Hopper, V. (1970). Chaucer's Canterbury tales. Hauppauge, USA: Barron's Educational Series, Inc.

Cheal, J. (2008a). Solving impossible problems. Carmarthen, UK: Crown House Publishing

Cheal, J. (2008b). Exploring the role of NLP in the management of organizational paradox. In P. Tosey (Ed), Current research in NLP (1 ${ }^{\text {st }}$ vol.) (pp. 35-50). Retrieved

from https://pdfs.semanticscholar.org/b1de/6262ff5dfbbdff5342d6761b76fc28 531cb9.pdf? ga=2.11066996.1921520363.1578996063$\underline{1215171703.1564393149}$

Clegg, S., \& Pina E Cunha, M. (2017). Organizational dialectics. in W. Smith, M. Lewis, P. Jarzabkowski \& A. Langley (Eds), The Oxford handbook of organizational paradox. Oxford, UK: Oxford University Press. doi:10.1093/oxfordhb/9780198754428.013.5

Dilts, R. (1990). Changing belief systems with NLP. Toronto, Canada: Meta Publications 
Training Dragons... The Dragon Archetype as the Contradictions, Paradoxes ... Gabriel Remus SUCIU

Dilts, R. (1994). Strategies of genius (1 ${ }^{\text {st }}$ vol.). Toronto, Canada: Meta Publications

Dilts, R. (1998). Double binds, part 1 \& part 2 [Video file]. Videotaped at the Institute for the Advanced Study of Health, $5^{\text {th }}$ annual conference.

Dilts, R. (2003). From coach to awakener. Toronto, Canada: Meta Publications

Dilts, R., \& DeLozier, J. (2000). Encyclopedia of systemic Neuro-Linguistic Programming and NLP new coding. Retrieved from http://www.nlpu.com/NLPU.html

Gardner, M. (1960). Mathematical puzzles of Sam Loyd (2nd vol.). Chicago, USA. Dover Publications, Inc.

Gardner, M. (1967). Les casse-tête mathématiques de Sam Loyd [Mathematical puzzles of Sam Loyd] (2nd vol.). Paris, France: Dunod

Greer, J. M. (2011). Monsters. Woodbury, USA: Llewellyn Publications.

Hayakawa, S. I. (1952). Language in thought and action. Crows Nest, Australia: George Allen \& Unwin LTD

Heller, J. (1996). Catch-22. New York, USA: Simon \& Schuster.

Holy Bible, American Standard Version. Retrieved from http://www.gospelhall.org/bible/bible.php?passage=Titus

Jung, C. G. (1960). Psychogenesis of mental disease (3 $3^{\text {rd }}$ vol.). Princeton, USA: Bollingen Series XX.

Jung, C. G. (1968). Analytical psychology. New York, USA: Vintage Books.

Jung, C. G. (1969). Archetypes and the collective unconscious (9th vol.). Princeton, USA: Bollingen Series XX

Jung, C. G. (2001). Four archetypes. Abingdon-on-Thames, UK: Rutledge.

Korzybski, A. (2000). Science and sanity. Forest Hills, USA: Institute of General Semantics.

Kostera, M. (2012). Organizations and archetypes. Cheltenham, UK: Edward Elgar

Lawley, J. (2000). Modelling the structure of binds and double binds. Retrieved from http://www.cleanlanguage.co.uk

Lawley, J. (2013). What are double binds? Retrieved from http://www.cleanlanguage.co.uk

Lawley, J., \& Tompkins, P. (2003). Metaphors in mind. Transformation through symbolic modelling. USA: The Developing Company Press

Loyd, S. (1914). Cyclopedia of puzzles. New York, USA: The Lamb Publishing Company.

Maier, N. (1930). Reasoning in humans. On direction. Journal of comparative psychology, 10(2), 115-143. doi:10.1037/h0073232

Mavrodes, G. (1963). Some puzzles concerning omnipotence. The Philosophical Review, 72(2), 221-223. doi:10.2307/2183106 
Moore, R. (2003). Facing the dragon. Asheville, USA: Chiron Publications.

Orwell, G. (1949). 1984. London, UK: Secker \& Warburg

Putnam, L., Fairhurst, G., \& Banghart, S. (2016). Contradictions, dialectics and paradoxes in organizations: A constitutive approach. The Academy of Management Annals, 10(1), 65-171. doi:10.1080/19416520.2016.1162421

Russell, B. (2010a). Principles of mathematics. Abingdon-on-Thames, UK: Rutledge Classics.

Russell, B. (2010b). The philosophy of logical atomism. Abingdon-on-Thames, UK: Rutledge Classics.

Satir, V. (1988). The new peoplemaking. Palo Alto, USA: Science and Behavior Books, Inc.

Satir, V., Banmen, J., Gerber, J., \& Gomori, M. (1991). The Satir model. Palo Alto, USA: Science and Behavior Books, Inc.

Savage, W. (1967). The paradox of the stone. The Pbilosophical Review, 76(1), 74-79. doi:10.2307/2182966

Scheerer, M. (1963). Problem-solving. Scientific American, 200(4), 118-132. doi:10.1038/scientificamerican0463-118

Suciu, G. (2011). Multiple intelligences. Revista de Asistenţă şi Mediere Socială, 49-59.

Watzlawick, P. (1976). How real is real? New York, USA: Vintage Books.

Watzlawick, P., Helmick Beavin, J., \& Jackson, D. (1967). Pragmatics of human communication. New York, USA: W.W. Norton \& Company, Inc.

Watzlawick, P., Weakland, J., \& Fisch, R. (1974). Change. Principles of problem formation and problem solving. New York, USA: W.W. Norton \& Company, Inc. 